\title{
CHEMICAL COMPOSITION OF SURGICAL SMOKE FORMED IN THE ABDOMINAL CAVITY DURING LAPAROSCOPIC CHOLECYSTECTOMY - ASSESSMENT OF THE RISK TO THE PATIENT
} \author{
ANDRZEJ SAPOTA ${ }^{3}$, and LECH SYLWESTER POMORSKI ${ }^{1}$ \\ ${ }^{1}$ Medical University of Lodz, Łódź, Poland \\ Department of General and Oncological Surgery \\ ${ }^{2}$ Nofer Institute of Occupational Medicine, Łódź, Poland \\ Department of Chemical Hazard \\ ${ }^{3}$ Medical University of Lodz, Łódź, Poland \\ Department of Toxicology
}

MIŁOSZ DOBROGOWSKI ${ }^{1}$, WIKTOR WESOŁOWSKI ${ }^{2}$, MAŁGORZATA KUCHARSKA ${ }^{2}$,

\begin{abstract}
Objectives: The aim of this study was to assess the exposure of patients to organic substances produced and identified in surgical smoke formed in the abdominal cavity during laparoscopic cholecystectomy. Material and Methods: Identification of these substances in surgical smoke was performed by the use of gas chromatography-mass spectrometry (GC-MS) with selective ion monitoring (SIM). The selected biomarkers of exposure to surgical smoke included benzene, toluene, ethylbenzene and xylene. Their concentrations in the urine samples collected from each patient before and after the surgery were determined by SPME-GC/MS. Results: Qualitative analysis of the smoke produced during laparoscopic procedures revealed the presence of a wide variety of potentially toxic chemicals such as benzene, toluene, xylene, dioxins and other substances. The average concentrations of benzene and toluene in the urine of the patients who underwent laparoscopic cholecystectomy, in contrast to the other determined compounds, were significantly higher after the surgery than before it, which indicates that they were absorbed. Conclusions: The source of the compounds produced in the abdominal cavity during the surgery is tissue pyrolysis in the presence of carbon dioxide atmosphere. All patients undergoing laparoscopic procedures are at risk of absorbing and excreting smoke by-products. Exposure of the patient to emerging chemical compounds is usually a one-time and short-term incident, yet concentrations of benzene and toluene found in the urine were significantly higher after the surgery than before it.
\end{abstract}

Key words:

Risk factor, Surgical smoke, Xenobiotics, Absorbtion, Urine analysis, Laparoscopy

The study was supported by the grant 1767/B/P01/2010/39 from the National Science Centre, Poland. Manager of grant: prof. Lech Sylwester Pomorski. Received: September 16, 2013. Accepted: February 18, 2014.

Corresponding author: M. Dobrogowski, Department of General and Oncological Surgery, Parzęczewska 35, 95-100 Zgierz, Poland (e-mail: miloszd@onet.pl). 


\section{INTRODUCTION}

Laparoscopic operations are beginning to dominate in most areas of operational treatment, and in the case of some of them they have become standard procedures. Indications for their application expand and new technical tools are continuously being refined and implemented to perform more and more complex procedures. Patients are also more likely to opt for this type of operation because of a shorter hospital stay and a faster recovery. Also, the cosmetic effect is more favorable (small scars). One of the most commonly performed laparoscopic surgery is resection of the gallbladder (cholecystectomy). This method has now become standard. During this operation, in order to prevent bleeding, coagulation of tissues is necessary as well as cutting them in the coagulation zone in the peritoneal cavity filled with carbon dioxide to the pressure of about $10-15 \mathrm{~mm} \mathrm{Hg}$. For this purpose, the apparatus for mono- or bipolar coagulation and an ultrasonic knife or other coagulating-cutting devices are used. These devices consist of an electric generator and high-frequency mono- and/or bipolar endings. Electric current is applied with a frequency that does not stimulate neuromuscular activity. Temperatures reached at the coagulating endings range from $100^{\circ} \mathrm{C}$ to $500^{\circ} \mathrm{C}$, and the zone of thermal injury to tissues reaches $4-5 \mathrm{~mm}$. During typical laparoscopic operations thermocoagulation of tissues in the atmosphere of carbon dioxide occurs. During this process, in the oxygen-free atmosphere a number of different chemical compounds, which can be potentially harmful to the health of both, patients and medical personnel, are formed and released. The characteristic sharp smell of the smoke released from abdominal cavity can be smelt in the operating theatre and it is also visible on the screen. The particular risk of exposure to the substances that are formed during such treatment is connected with the possibility of their direct absorption through peritoneum and their penetration into blood and other body fluids [1,2].

The proof of their absorption may be the presence of these compounds or their metabolites in blood and urine. Urine is a filtrate of blood and it contains toxic substances and their metabolites present in blood. Therefore, analysis of urine samples is an important source of information concerning functioning of the body, as well as its exposure to harmful substances. Whereas smoke production during laparoscopic surgeries is well documented in world literature [1-7], the analysis of urine samples of patients undergoing laparoscopic procedures in order to assess the potential exposure to such substances has not been performed yet.

A number of studies, such as those conducted by Barrett et al. [7], show the presence of chemical compounds of different structure and toxicity, which mostly occur in low to trace concentrations, in the smoke produced as a result of tissue thermocoagulation. The identified compounds include aliphatic hydrocarbons, aromatic hydrocarbons (including carcinogenic benzene), aldehydes, nitriles, amines, phenols and others. During a laparoscopic surgery patients breathe with the help of anesthetic equipment that sucks clean air from the outside of the operating theatre. Therefore, exposure of the patient depends only on the concentration of compounds released from the fat tissue or produced during tissue pyrolysis and the efficiency of their absorption into the bloodstream through peritoneum. Biological monitoring remains the only way to assess exposure of the patient and the tremendous progress and development of new analytical methods make it possible to measure quantitatively small, or even trace amounts of these substances. Similar studies to the one we performed have not been done before. This study offers us a glimpse into the threat posed by new surgical techniques, such as minimally invasive operations, which are becoming more and more popular. We have confirmed the presence of 
many chemical compounds, which are released during the pyrolysis of tissues, in the abdomen. Next, we have proved that some of these compounds are absorbed by peritoneum into the body of the operated patients. For the first time, we have identified dioxins in the surgical smoke created during laparoscopic cholecystectomy.

We have proved that the concentrations of benzene and toluene were significantly higher in patients after the surgery than before it. Our results showed that urine samples are a good source of information on occupational exposure as well as the dangers posed by modern medicine.

\section{OBJECTIVES}

1. Identification of the main chemical compounds produced in the abdomen during laparoscopic cholecystectomy.

2. Quantitative measurement of the concentrations of toxic chemicals excreted in the urine after the surgery.

3. Selection of exposure biomarkers useful for assessing the health risk of the patients exposed to these compounds.

\section{MATERIAL AND METHODS}

\section{Ethical issues}

The study was approved by the Ethics Committee of the Medical University of Lodz, Poland (approval No. RNN/195/08/K). The patients were informed before the surgery about the conduct of the research and voluntarily agreed to have samples of their urine collected for analysis.

Sixty nine women and 13 men were randomly selected for the study. The age of the operated patients ranged from 18 to 77 years. The average operation time was $80 \mathrm{~min}$. Based on the survey, occupational and environmental exposure to aromatic hydrocarbons was excluded.
The operating theater of the hospital in Zgierz consists of 4 operating rooms, which make an enclosed space together with the preparation rooms, the sterilization room, etc. The study was conducted in the operating theater during laparoscopic procedures.

The first step of the study was performed according to Figure 1.

For identification purposes, gas samples were taken directly from the cable connected to the main working trocar through which, during operations, the gases escape from the abdominal cavity. The samples were taken by the use of measuring sets appropriate for the expected groups of substances. The expected substances included carbonyl compounds (aldehydes, ketones), volatile organic compounds (aliphatic hydrocarbons, aromatic hydrocarbons, alcohols) and polychlorinated dibenzodioxins and furans (PCDD/PCDF). In front of each measuring set, a humidity capacitors were installed, and their content was analyzed with respect to the presence of volatile substances by the use of the SPME technique.

To perform determinations of volatile organic compounds, a measurement set was used, consisting of a gas chromatograph manufactured by Agilent Technologies $6890 \mathrm{~N}$, a mass detector 5973, a split/splitless injector chamber, an INNOWAX capillary column (length: $60 \mathrm{~m}$, diameter: $0.25 \mathrm{~mm}$, film thickness of the stationary phase: 0.5 microns) and a computer data acquisition station. The analyses were performed using a programmable oven temperature of the column $\left(40^{\circ} \mathrm{C}(2 \mathrm{~min}), 5^{\circ} \mathrm{C} / \mathrm{min} \rightarrow 80^{\circ} \mathrm{C}\right.$ $(0 \mathrm{~min}), 20^{\circ} \mathrm{C} / \mathrm{min} \rightarrow 180^{\circ} \mathrm{C}(15 \mathrm{~min})$ ), the temperature of the split/splitless injection chamber $-200^{\circ} \mathrm{C}$.

Data acquisition was performed in the selective ion monitoring (SIM) mode and scanning at the same time. The scanning range ranged from $10 \mathrm{Da}$ to $250 \mathrm{Da}$. The signal for the SIM was collected for specific masses of aromatic hydrocarbons:

- Group 1 (benzene) - 50.0, 51.0, 52.0, 78.0.

- Group 2 (toluene) - 65.0, 91.0,92.0. 
- Group 3 (ethyl benzene, xylene) - 51.0, 65.0, 91.0, 105.0, 106.0.

- Group 4 (naphthalene, biphenyl, alkyl derivatives of benzene C9-C10) - 105.0, 120.0, 128.0, 134.0, 154.0.

Determination of PCDD/PCDF was conducted using isotope dilution high resolution chromatography/tandem mass spectrometry (ID-HRGC/MS-MS) on a Thermo Scientific GCQ-1100/Trace2000 system equipped with Xcalibur data acquisition and analysis software. Separation was performed on a $30 \mathrm{~m} \times 0.25 \mathrm{~mm}$ i.d. DB5MS J\&W capillary column of $25 \mu \mathrm{m}$ film and DB1730 $\mathrm{m} \times 0.25 \mathrm{~mm}$ i.d. DB5MS J\&W capillary column of $25 \mu \mathrm{m}$ film. A sample of $2.5 \mu 1$ volume was injected into the SSL injector at $260^{\circ} \mathrm{C}$. The $\mathrm{GC}$ oven was programmed as follows: the initial temperature of $130^{\circ} \mathrm{C}$ was held for $3 \mathrm{~min}$, then temperature jump of $50^{\circ} \mathrm{C} / \mathrm{min}$ to $180^{\circ} \mathrm{C}$, then another temperature jump $-2^{\circ} \mathrm{C} / \mathrm{min}$ to $270^{\circ} \mathrm{C}$. Finally, the temperature jump was $20^{\circ} \mathrm{C} / \mathrm{min}$ to $300^{\circ} \mathrm{C}$ and it was held

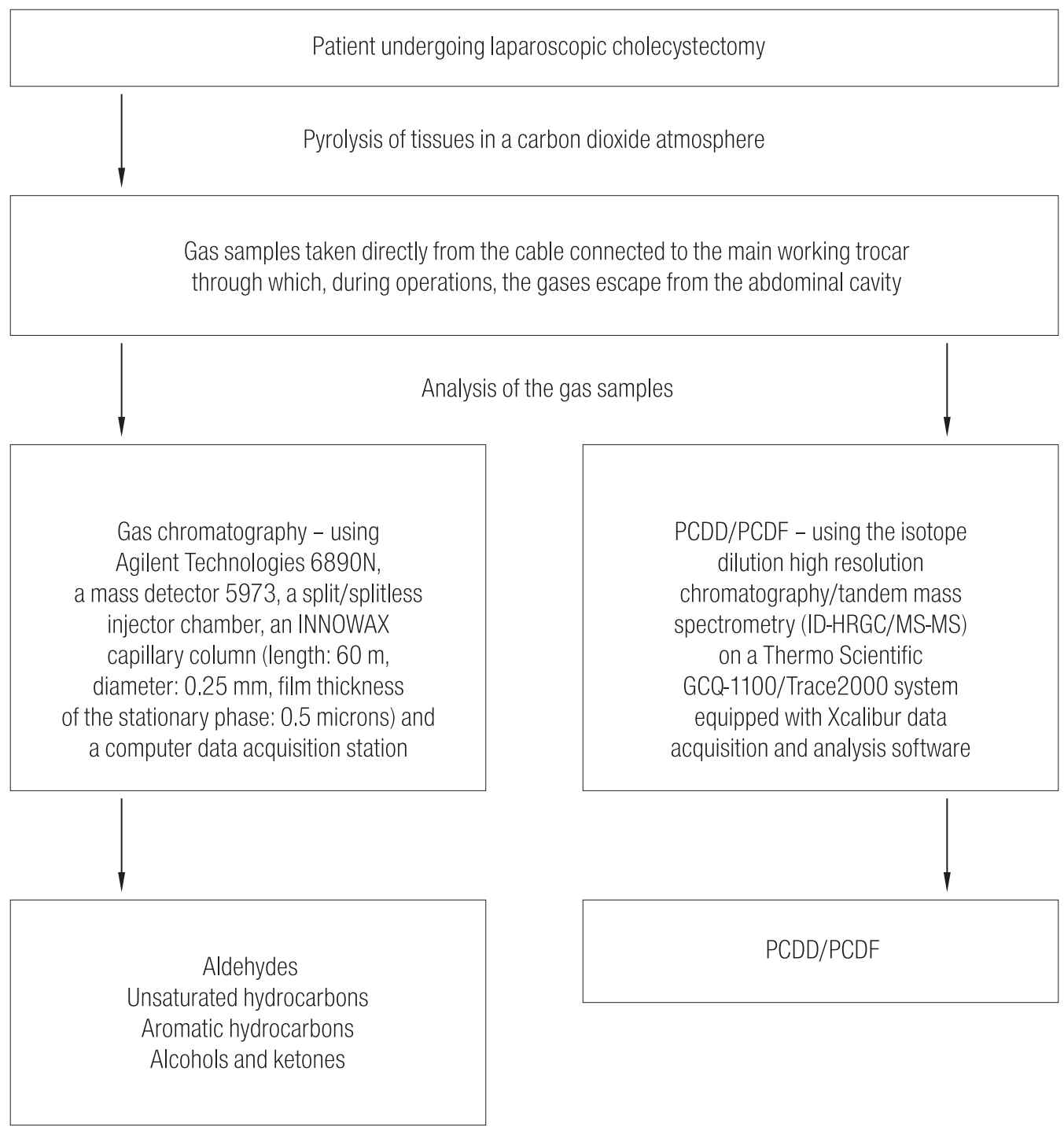

PCDD - polychlorinated dibenzodioxins; PCDF - polychlorinated dibenzofurans.

Fig. 1. Qualitative identification of the composition of gases formed in the peritoneal cavity during laparoscopic cholecystectomy 


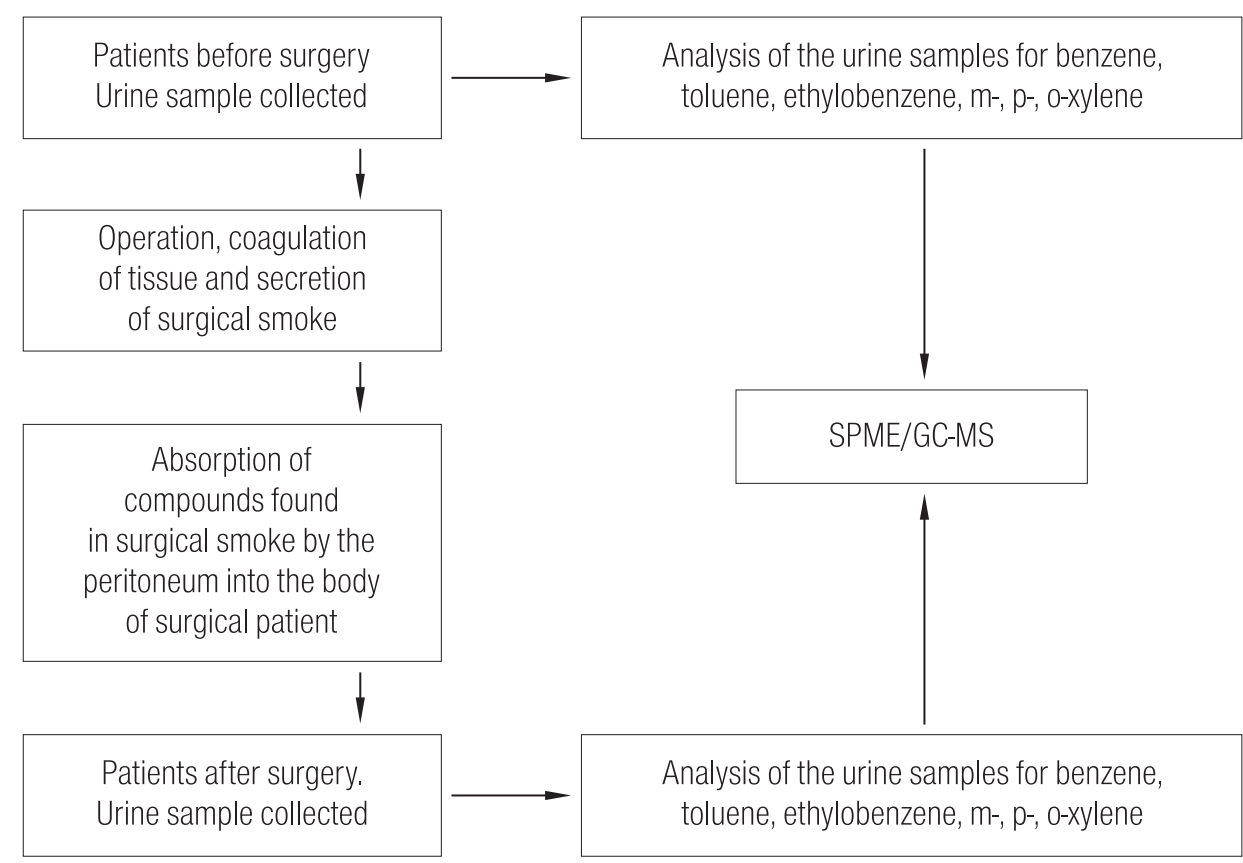

SPME/GC-MS - soild-phase microextraction / gas chromatography - mass spectrometry.

Fig. 2. Urine sampling and analysis

for 5 min. PCDD/PCDF were determined only in 20 randomly collected gas samples.

The next stage of the study (Figure 2) was to test whether the chemicals produced in the abdomen are absorbed into the body of a surgical patient and excreted in the urine. Upon admission to the hospital for the planned surgery, the patients had urine samples collected. Volume and specific gravity measurements were performed. Then, $2 \mathrm{ml}$ of urine were taken in 3-4 min using a glass pipette - and it was dispensed to the previously prepared chromatographic vials containing $1 \mathrm{~g}$ of $\mathrm{NaCl}$. After capping, the vials were placed in a refrigerator at $4^{\circ} \mathrm{C}$ until analysis. During their hospital stay, the patients did not smoke cigarettes and were not exposed to cigarette smoke. The hospital is not situated near a busy street. All operations were conducted in the same operating theater using identical sets of tools. All patients were anesthetized using the same method and the same set of anesthetic equipment.

Immediately after the surgery, each patient was taken to the specially designated recovery room, where he/she stayed until the next day. The urine first excreted after the surgery (5-12 h after the surgery) was collected into a clean glass container. The volume and specific gravity of the urine given to analysis were measured. Then, similarly as before, $2 \mathrm{ml}$ of urine were measured with a glass pipette, into previously prepared chromatographic vials containing $1 \mathrm{~g}$ of $\mathrm{NaCl}$. The capped vials containing samples of urine were stored in a refrigerator at $4^{\circ} \mathrm{C}$ until analysis.

\section{Methodology for quantitative determinations of urine samples collected before and after the surgery}

The content of volatile organic compounds (benzene, toluene, ethylbenzene, xylene) was determined in urine by the use of solid phase microextraction gas chromatography (SPME-GC-MS). The analyses were conducted on a HP 6890 gas chromatograph with a HP 5973 mass detector, split injector, and capillary column (HP-INNOWAX) using the method described by Fustinioni et al. [8]. 


\section{Methods of statistical analysis}

For statistical evaluation of the research results the nonparametric Wilcoxon test for paired observations was used [9]. The decision to use the non-parametric test was taken after verification with the Shapiro-Wilk test and its result being abnormal distributions of the tested variables. The level of significance used for statistical tests was $\alpha=0.05$.

\section{Quality control}

Internal quality control (IQC) procedures implemented in the laboratory were based on the use of control and calibration of samples which were included in the analytical procedures and which were prepared in the same way as the samples. They were also based on the use of internal standard (ISTD). Because of the fact that reference material was not commercially available, quality control samples were prepared in the laboratory by spiking a sample from the volunteers. Internal quality samples (IQS) were always injected at the beginning, every 10 samples and at the end of a sequence.

\section{RESULTS}

The results of the qualitative chromatographic analysis of surgical smoke are shown in Table 1.

As presented in the table, during coagulation in the abdominal cavity, about 40 substances, different in terms of their chemical structure, such as: aldehydes, unsaturated and saturated hydrocarbons having conjugated double and triple bonds (e.g., alcohols, ketones) as well as aromatic hydrocarbons and dioxins, were formed and identified. Aromatic hydrocarbons found in the surgical smoke include benzene and its alkyl derivatives (e.g., toluene, ethylbenzene, xylenes). Also, the presence of polychlorinated dioxins and furans was reported, including 2,3,7,8-TCDD. Mass spectra of the selected compounds confirming their chemical structure are presented in Figure 3.

For some toxic substances identified in the laparoscopic smoke, biological monitoring was carried out based on the measurement of the concentrations of these xenobiotics in the urine of the patients, collected before and after the

Table 1. The main components identified in the samples of laparoscopic smoke

\begin{tabular}{|c|c|c|c|c|c|}
\hline Aldehydes* & Unsaturated hydrocarbons & Aromatic hydrocarbons & $\begin{array}{c}\text { Alcohols } \\
\text { and ketones }\end{array}$ & Other & $\mathrm{PCDD} / \mathrm{PCDF}^{* * *}$ \\
\hline Formaldehyde & but-1-en-3-yn (vinylacetylene) & benzene & isopropyl alcohol & acrylonitrile & 2,3,7,8-TCDD \\
\hline Acetone & butane-1,3-diyn & ethylbenzene & ethyl alcohol & acetonitrile & 1,2,3,7,8-PCDD \\
\hline Acetaldehyde & phenylacetylene & etylobenzen & acetone & & 1,2,3,4,7,8-HxCDD \\
\hline Propionaldehyde & 1-phenylcyclohexene & m-, p-, o-xylene & & & 1,2,3,4,6,7,8-HpCDD \\
\hline Methacrolein & & cumene ${ }^{* *}$ & & & OCDD \\
\hline Butyraldehyde & & o-, m-, p-ethyl toluene** & & & 2,3,7,8-TCDF \\
\hline Benzaldehyde & & mesitylene ${ }^{* *}$ & & & 1,2,3,7,8-PCDF \\
\hline Valeraldehyde & & pseudocumene ${ }^{* *}$ & & & 1,2,3,6,7,8-HxCDF \\
\hline \multirow[t]{2}{*}{ Hexyl aldehyde } & & hemimeliten** & & & OCDF \\
\hline & & naphthalene & & & \\
\hline
\end{tabular}

PCDD - polychlorinated dibenzodioxins; PCDF - polychlorinated dibenzofurans.

TCDD, PCDD, HxCDD, HpCDD, OCDD, TCDF, PCDF, HxCDF, OCDF - congeners of PCDD/PCDF (dioxins).

* Identified based on the retention time of the derivative with 2,4-dinitrophenylhydrazine.

** Identified based on the retention time of the signal recorded in the selective ion monitoring (SIM) mode.

*** Identified based on the retention time of the signal recorded in the SIM mode using isotopic patterns. 

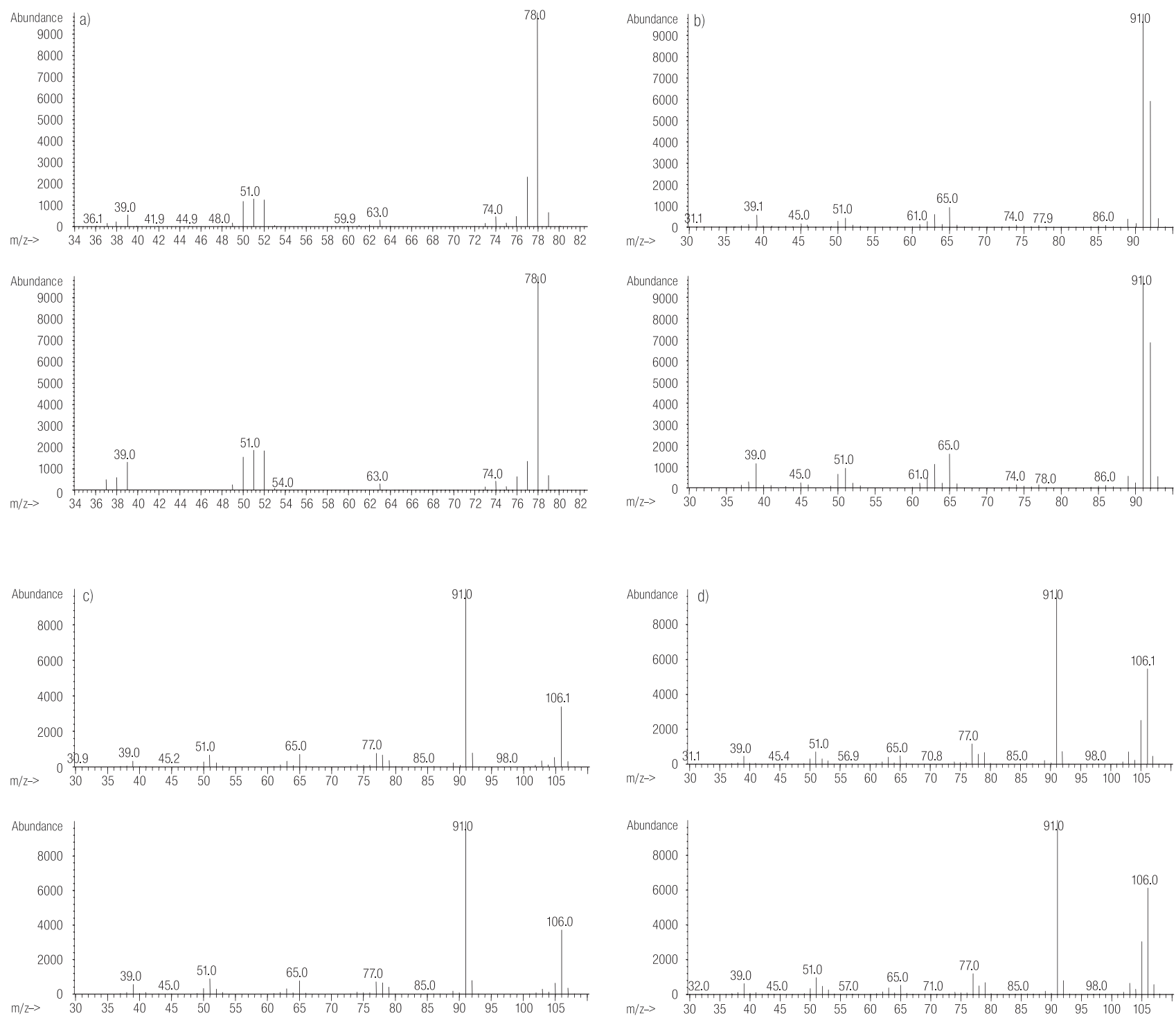

Fig. 3. Peak identification protocols tested (up) with a reference mass spectrum of the library Willey7 (bottom), respectively for a) benzene, b) toluene, c) ethylbenzene, and d) p-xylene

surgery. This study included substances for which the assay methods in the urine were validated and which provide a satisfactory level of determination.

Results concerning the urine samples analyzed with respect to the presence of benzene, toluene, xylene and ethylbenzene are shown in Table 2 and in Figure 4.

As shown in Table 2 and Figure 5, concentration of benzene in the urine of the patients after the surgery was on average $0.867 \pm 0.143$ and it was about 3 times higher than before the surgery $(0.280 \pm 0.045)$. In the case of toluene, the average concentrations of the compound in the urine of the patients after the surgery were also significantly higher than before it, although this difference was not so emphatic: $0.718 \pm 0.110$ (before the surgery) compared to $1.051 \pm 0.188$ (after the surgery).

No significant differences were found between the concentrations of ethylbenzene and xylenes $(\mathrm{m}, \mathrm{o}, \mathrm{p})$ determined pre- and postoperatively. 
Table 2. Average concentrations of the selected substances in the urine samples taken from the 82 patients before and after the surgery

\begin{tabular}{|c|c|c|c|c|}
\hline \multirow[t]{2}{*}{ Tested substance } & \multicolumn{3}{|c|}{$\begin{array}{c}\text { Concentration } \\
(\mu \mathrm{g} / \mathrm{l})\end{array}$} & \multirow{2}{*}{$\begin{array}{l}\mathrm{p} \text { in the test comparing } \\
\text { the averages for } \\
\text { dependent variables }\end{array}$} \\
\hline & $\mathrm{M} \pm \mathrm{SEM}$ & $\mathrm{Me}$ & range & \\
\hline \multicolumn{5}{|l|}{ Benzene } \\
\hline $\begin{array}{l}\text { before surgery } \\
\text { after surgery }\end{array}$ & $\begin{array}{l}0.280 \pm 0.045 \\
0.867 \pm 0.143\end{array}$ & $\begin{array}{l} \pm 0.150 \\
\pm 0.310\end{array}$ & $\begin{array}{l}0.000-2.240 \\
0.020-6.060\end{array}$ & $<0.0005$ \\
\hline \multicolumn{5}{|l|}{ Toluene } \\
\hline $\begin{array}{l}\text { before surgery } \\
\text { after surgery }\end{array}$ & $\begin{array}{l}0.718 \pm 0.110 \\
1.051 \pm 0.138\end{array}$ & $\begin{array}{l} \pm 0.450 \\
\pm 0.675\end{array}$ & $\begin{array}{l}0.080-6.850 \\
0.140-7.660\end{array}$ & 0.039 \\
\hline \multicolumn{5}{|l|}{ Ethylbenzene } \\
\hline $\begin{array}{l}\text { before surgery } \\
\text { after surgery }\end{array}$ & $\begin{array}{l}1.518 \pm 0.104 \\
1.765 \pm 0.164\end{array}$ & $\begin{array}{l} \pm 1.480 \\
\pm 1.480\end{array}$ & $\begin{array}{l}0.110-4.900 \\
0.090-6.220\end{array}$ & 0.100 \\
\hline \multicolumn{5}{|l|}{ M-, p-xylene } \\
\hline $\begin{array}{l}\text { before surgery } \\
\text { after surgery }\end{array}$ & $\begin{array}{l}2.082 \pm 0.173 \\
1.876 \pm 0.233\end{array}$ & $\begin{array}{l} \pm 1.880 \\
\pm 1.260\end{array}$ & $\begin{array}{l}0.150-6.560 \\
0.110-9.000\end{array}$ & 0.268 \\
\hline \multicolumn{5}{|l|}{ O-xylene } \\
\hline $\begin{array}{l}\text { before surgery } \\
\text { after surgery }\end{array}$ & $\begin{array}{l}1.042 \pm 0.114 \\
1.064 \pm 0.112\end{array}$ & $\begin{array}{l} \pm 0.785 \\
\pm 0.725\end{array}$ & $\begin{array}{l}0.060-6.060 \\
0.050-4.720\end{array}$ & 0.883 \\
\hline
\end{tabular}

M - mean; SEM - standard error of measurement; Me - median.

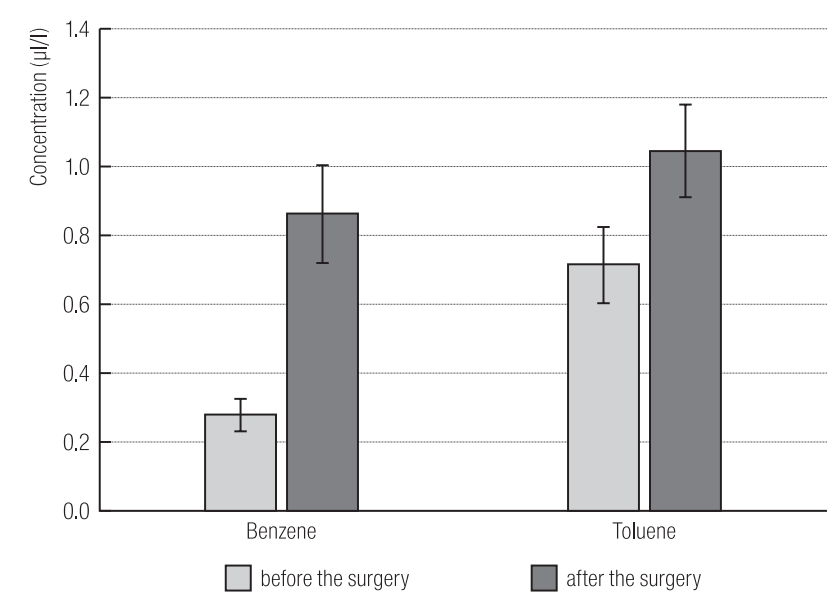

Fig. 4. Average concentrations of benzene and toluene in the urine samples collected from the patients before and after the surgery

\section{DISCUSSION}

Surgical smoke from abdominal cavity may pose a hazard to both, the operating room staff and the patients since it contains chemical compounds. There are many documented studies, which show that the smoke plume contains a vast array of chemical compounds, including aliphatic hydrocarbons, aromatic hydrocarbons such as benzene and its alkyl derivatives, as well as aldehydes, nitriles, amines, and other substances [4-7]. In contrast to other authors, we have also found traces of polychlorinated dioxins and furans, including the highly toxic 2,3,7,8-TCDD. Some xenobiotics identified in the laparoscopic smoke may have mutagenic and carcinogenic effect.

There is a risk of their direct or indirect impact on genetic material. In the case of patients undergoing laparoscopic procedures who breathe with anesthesia equipment, which draws in fresh air from the outside of the operating theatre, the exposure to these potentially harmful compounds is associated with the risk of direct absorption (into the bloodstream through peritoneum) of a number of substances that are either released from the fat tissue or 
produced in the pyrolysis process during thermocoagulation of the tissues.

Therefore, the only way to assess the exposure of the patients is biological monitoring. So far such tests have not been performed, hence the assay results described in our work concerning the selected compounds in the urine collected from the patients before and after the operation are novel and they indicate that toxic compounds present in the smoke are absorbed into the body. Previous studies carried out by various authors included only the analysis of the air (surgical smoke).

In the literature, there are few works on biological monitoring based on the measurement of unchanged compounds excreted in the urine, but they refer only to occupationally exposed workers [10-14]. These works have demonstrated a high correlation between concentrations of various solvents in the air of the working environment, and their concentration in the urine. Biological monitoring of the exposure to benzene and toluene is particularly well-documented. In the past, it was based on the concentration measurements of the metabolites of these substances in the urine. Great progress and development of new analytical methods now allow for a quantitative measurement of even very small (trace) amounts of unchanged compounds, including benzene and toluene [10-14].

It has been reported by other authors that in the smoke produced during laparoscopy more than 40 different compounds of different structure and belonging to different groups, such as aldehydes, unsaturated and saturated hydrocarbons having conjugated double and triple bonds (e.g., alcohols and ketones), as well as aromatic hydrocarbons such as benzene and its alkyl derivatives (toluene, ethylbenzene, xylenes), may be detected. Our study confirmed formation of compounds from these groups.

Then for the selected toxic compounds identified in the surgical smoke, we performed biological monitoring based on the examination of the concentrations of the selected xenobiotics in the urine samples collected before and after the surgery.

The study showed that the concentrations of benzene and toluene identified in the urine of the patients after the surgery were significantly higher than their concentrations before the surgery, which is direct evidence that during such operations these compounds are produced and absorbed into the blood. The obtained results indicate the possibility of implementing biological monitoring to assess the potential risk for the patients undergoing this type of surgery.

In theory, the absorbed compounds may pose a potential risk of distant health effects. It should be borne in mind that benzene, concentration of which in the urine of the patients after the laparoscopic surgery was more than 3 times higher than before the operation, is classified by the International Agency for Research on Cancer (IARC) as Group 1 human carcinogen and its role as a leukemogen has been clearly demonstrated through a number of epidemiological studies. Other effects on the hemopoietic system include leukopenia, agranulocytosis, anemia, pancytopenia and the myelodysplastic syndrome. Benzene is also considered a leukemogenic factor in humans. Benzene is a human clastogen: chronic exposure leads to consistent structural and numerical chromosomal aberrations in lymphocytes and bone marrow cells which may be recorded for at least 5 years after cessation of (occupational) exposure [15-22].

Benzene diffuses across the placenta and is considered to be fetotoxic. It is not thought to be a teratogen and there is currently no evidence that it causes reproductive effects in humans. Therefore, it appears that laparoscopic procedures in pregnant women may be a subject to some risk. Laparoscopy, as a diagnostic-operation technique, is currently regarded as a method safe in pregnant women and is increasingly being used in obstetrics [23,24]. The scope of indications for laparoscopy in pregnancy relates mainly to lithiasis and cholecystitis (the so-called acute abdomen). 
Most of these procedures are performed in the first (33\%) and second trimester of pregnancy (56\%) [24]. Although in all the cases there is obligatory pre- and post-operative monitoring of the wellness of the fetus and the maternal end levels of the expiratory carbon dioxide concentration, no additional risk has ever been taken into consideration for the substances that are present in the surgical smoke, such as benzene or 2,3,7,8-TCDD, which are carcinogenic compounds with a proven harmful effect on the fetus.

The second chemical compound for which we revealed a significant increase in the urine of the operated patients was toluene. Although toluene, unlike benzene, does not have carcinogenic effect, there is a number of developmental consequences, particularly neurodevelopmental changes, that have been reported in children of the women who abused toluene during pregnancy. The effects recorded in children exposed in utero to toluene include central nervous system (CNS) dysfunction, attention deficits and developmental delay/mental deficiency [25].

Since some experimental tests have shown the possibility of interaction between benzene and other chemicals, including toluene, such interaction cannot be ruled out in the exposed patients [26,27].

Summing up, we can conclude that although the quantitative analysis showed relatively low levels of the selected compounds in the smoke and determined in the urine, it should be borne in mind that:

1. Concentrations of the compounds tested in the urine make only a small percentage of the total absorbed dose (e.g. benzene).

2. The presence of a mixture of numerous toxic compounds, even in trace amounts, in the urine, due to the possibility of interaction can significantly increase their overall toxicity potential.

3. Despite the short time of exposure (the duration of the operation does not exceed $2 \mathrm{~h}$ ) and relatively low concentrations, one cannot rule out the potential threat of carcinogenic compounds (e.g. benzene).
In addition, to reduce or eliminate the potential risk of exposure to the compounds produced during tissue pyrolysis, which can be harmful to the fetus, one should consider using gasless laparoscopic techniques in pregnant women. A significant proportion of these operations, $>50 \%$ has already been performed in women who suffer from gallstones and are of childbearing age. In this case, the elevation of the abdominal wall can be applied [28-31], or bipolar devices can be used for laparoscopic purposes causing lesser production of the toxic smoke [31].

\section{CONCLUSION}

1. During laparoscopic surgery, in the abdominal cavity smoke is produced, which was shown to contain many potentially dangerous chemicals.

2. The smoke source is probably thermocoagulation of the tissues and their pyrolysis that take place during the procedure.

3. The patient's exposure to the produced chemicals is usually a one-time and short-term one, and the concentrations of benzene and toluene found in the urine are relatively low.

4. The presence of chemical compounds in the urine is a result of their absorption by peritoneum and their circulation in the body.

5. The results indicate the possibility of establishing biological monitoring to determine the concentrations of benzene and toluene in the urine as major biomarkers of the patients' exposure during laparoscopic procedures.

\section{REFERENCES}

1. Hensman C, Baty D, Willis RG, Cuschieri A. Chemical composition of smoke produced by high - frequency electrosurgery in a closed gaseous environment. Surg Endosc. 1998;12:1017-19. 
2. Wu JS, Luttman DR, Meininger TA, Soper NJ. Production and systemic absorption of toxic byproducts of tissue combustion during laparoscopic surgery. Surg Endosc. 1997;11:1075-9.

3. Alp E, Bijl D, Bleichrodt RP, Hansson B, Voss A. Surgical smoke and infection control. J Hosp Infect. 2006;62:1-5.

4. Nezhat C, Winer WK, Nezhat F, Nezhat C, Forrest D, Reeves WG. Smoke from laser surgery: Is there a health hazard? Lasers Surg Med. 1987;7:376-82.

5. Hensman C, Baty D, Willis RG, Cuschieri A. Chemical composition of smoke produced by high - frequencyelectrosurgery in a closed gaseous environment. Surg Endosc. 1998;12:1017-19.

6. Kokosa JM, Eugene J. Chemical composition of laser - tissue interaction smoke plume. J Laser App. 1989;3:59-63.

7. Barrett WL, Garber SM. Surgical smoke: A review of the literature. Is this just a lot of hot air? Surg Endosc. 2003;17(6):979-87.

8. Fustinoni S, Buratti M, Giampiccolo R, Brambilla G, Foa V, Colombi A. Comparison between blood and urinary toluene as biomarkers of exposure to toluene. Int Arch Occup Environ Health. 2000;73:389-96.

9. Gibbons JD, Chakraborti S. Nonparametric Statistical Inference. 5th ed. Boca Raton: Chapman \& Hall/CRC; 2011.

10. Wang BL, Takigawa T, Takeuchi A, Yamasaki Y, Kataoka H, Wang DH, et al. Unmetabolized VOCs in urine as biomarkers of low level exposure in indoor environments. J Occup Health. 2007;49:104-10.

11. Waidyanatha S, Rothman N, Fustiononi S, Smith M, Hayes RB, Bechtold W, et al. Urinary benzene as biomarker of exposure among occupationally exposed and unexposed subjects. Carcinogenesis. 2001;22(2):279-86, http://dx.doi. org/10.1093/carcin/22.2.279.

12. Senzolo C, Silvano F, Pavoni B. Environmental and biological monitoring of occupational exposure to organic micropollutants in gasoline. Chemosphere. 2001;44:67-82, http:// dx.doi.org 10.1016/S0045-6535(00)00364-7.

13. Janasik B, Jakubowski M, Wesołowski W, Kucharska M. Unmetabolized VOCs in urine as biomarkers of low level occupational exposure. Int J Occup Med Environ Health. 2010;23(1):21-6, http://dx.doi.org/10.2478/v10001010-0003-x.

14. Krämer Alkalde T, do Carmo Ruaro Peralba M, Alcaraz Zini C, Bastos Caramão E. Quantitative analysis of benzene, toluene, and xylenes in urine by means of headspace solidphase microextraction. J Chrom A. 2004;1027:37-40, http:// dx.doi.org/10.1016/j.chrome.2003.09.007.

15. WHO International Agency for Research on Cancer. Benzene. IARC Monograph Suppl. 1987;7:120-2.

16. WHO International Programme on Chemical Safety. Benzene [Internet]. Geneva: Environmental Health Criteria 150; 1993 [cited 2013 Sept 10]. Available from: http:// www.inchem.org/documents/ehc/ehc/ehc150.htm.

17. Smith MT. Overview of benzene-induced aplastic anaemia. Eur J Haematol Suppl. 1996;60:107-10.

18. Kuang S, Liang W. Clinical analysis of 43 cases of chronic benzene poisoning. Chem Biol Interact. 2005;153-4:129-35, http://dx.doi.org/10.1016/j.cbi.2005.03.038.

19. Wong $\mathrm{O}, \mathrm{Fu} \mathrm{H}$. Exposure to benzene and non-Hodgkin lymphoma, an epidemiologic overview and an ongoing casecontrol study in Shanghai. Chem Biol Interact. 2005;153-4: 33-41, http://dx.doi.org/10.1016/j.cbi.2005.03.038.

20. Schnatter AR, Rosamilia K, Wójcik NC. Review of the literature on benzene exposure and leukemia subtypes. Chem Biol Interact. 2005;153-4:9-21, http://dx.doi.org/10.1016/ j.cbi.2005.03.039.

21. Lamm SH, Engel A, Byrd DM. Non-Hodgkin lymphoma and benzene exposure; A systematic literature review. Chem Biol Interact. 2005;153-4:231-7, http://dx.doi.org/10.1016/ j.cbi.2005.03.027.

22. Smith MT. The mechanism of benzene-induced leukemia: A hypothesis and speculations on the causes of leukemia. Environ Health Perspect. 1996;104(6):1219-25.

23. Corneille MG, Gallup TM, Bening T, Wolf SE, Brougher C, Myers JG, et al. The use of laparoscopic surgery in pregnancy: Evaluation of safety and efficacy. Am J Surgery. 2010;200: 363-7, http://dx.doi.org 10.1016/j.amjsurg.2009.09.022. 
24. Klimek M, Wojtyś A, Wiecheć M, Kempf-Haber M, Wolak J. [Laparoscopy during pregnancy]. Gin Prakt. 2003;11(4): 3940. Polish.

25. Donald JM, Hooper K, Hopenhayn-Rich C. Reproductive and developmental toxicity of toluene: A review. Environ Health Perspect. 1991;94:237-44.

26. Sato A, Vakajima T. Dose-depondent metabolic integration between benzene and toluene in vivo and in vitro. Toxicol Appl Pharmracol. 1979;48:249-56.

27. Pollini G, Biscaldi GP, Robustelli della Cuna G. Chromosome changes of the lumphocytes discovered after five years in subjects with benzolic hemopathy. Med Lav. 1969;60(12): 743-58.

28. Eurosurgery 96. Gasless laparoscopic cholecystectomy. Sixth European Congress of Surgery, Rome, Italy, 15-18 Octo- ber 1996, Br J Surgery. 1996;83(Suppl S2):1-64, http:/dx.doi. org/10.1002/bjs.1800831402.

29. Paolucci V, Gutt CN, Schaeff B, Encke A. Gasless laparoscopy in abdominal surgery. Surg Endosc. 1995;5(9):497-500.

30. Barwijuk A, Litmanowicz M, Jankowska S. [Gasless laparoscopic hysterectomy in endometrial cancer - preliminary report]. Przegl Ginekol-Polozn. 2005;5(2):87-9. Polish.

31. Hübner M, Sigrist MW, Demartines N, Gianella M, Clavien PA, Hahnloser D. Gas emission during laparoscopic colorectal surgery using a bipolar vessel sealing device: A pilot study on four patients. Patient Saf Surg. 2008 [cited 2013 Sept 10];2:22 [about 5 p.]. Available from: http://dx.doi. org/10.1186/1754-9493-2-22.

This work is available in Open Access model and licensed under a Creative Commons Attribution-NonCommercial 3.0 Poland License - http://creativecommons.org/ licenses/by-nc/3.0/pl/deed.en. 